\title{
Valorization of Algerian Sand for Photovoltaic Application
}

\author{
S. Anas BoussaA ${ }^{a *}$, A. Kheloufi ${ }^{a}$, N. Boutarek Zaourar ${ }^{b}$ And F. Kerkar ${ }^{a}$ \\ ${ }^{a}$ Centre de Recherche en Technologie des Semi-conducteurs pour L'énergétique (C.R.T.S.E), \\ 02 Bd Frantz Fanon B.P. 140 Alger 7 Merveilles, Alger 16200
}

${ }^{b}$ Laboratoire des Technologies des Matériaux, USTHB, B.P. 32 El Alia, Bab Ezzouar, Alger 16111, Algérie

Extracting quartz from sand, as well as extracting silicon from quartz requires knowledge of the physical and chemical properties of quartz found in the sand. In this work the chemical composition, the crystallographic phase, crystal system, space group, unit cell parameters, the absorption bands, the granulometric analysis and the microscopic observations of quartz in the sand from Mostaganem (Algeria) region have been carried out using X-ray fluorescence, X-ray diffraction, infrared spectroscopy, sifting, optical and scanning electron microscopy in order to determine the rate and the nature the crystallinity of its various components and to discover a layer rich in silica, containing a sufficient reserve to feed a unit manufacturing pure silicon starting from silica. The study is driven by current economic importance of the silicon application in the field of photovoltaic solar cells. The X-ray fluorescence indicates that Mostaganem sand has got a very good purity (99.5\% silica). The crystallographic parameters of Mostaganem sand have been determined through analysis of X-ray diffraction. The following parameters were found, hexagonal crystal system, space group P3221, unit cell parameters: $a=b=4.9030 \AA, c=5.3999 \AA$. The infrared absorption spectrum of studied sand exhibits absorption bands characterizing the $\mathrm{SiO}_{2}$ compound, due to $\mathrm{Si}-\mathrm{O}-\mathrm{Si}$ and $\mathrm{Si}-\mathrm{O}$ aggregates and others. The granulometric analysis determines the percentage of the various fraction of the grain. The microscopy observation gives the shape of the grain. The results show finally that Mostaganem sand has got good proprieties for the photovoltaic application.

DOI: 10.12693 /APhysPolA.130.133

PACS/topics: 88.40.jj

\section{Introduction}

Quartz is one of the most abundant compounds in the Earth's crust. It is a crystalline form of silica. Silica is most generally found in nature as quartz, as well as in various living organisms. In many parts of the world, silica is the major constituent of sand. Silica is one of the most complex and most abundant families of materials, existing in form of several minerals. It is the basic mineral of sedimentary rocks which are formed by the deposition of sand. It is also found in sand dunes.

Silicate minerals are the name given to a group of minerals composed of silicon and oxygen, the two most abundant elements in the earth's crust. Silica is found commonly in the crystalline state and rarely in the amorphous state. It is composed of one atom of silicon and two atoms of oxygen resulting in the chemical formula $\mathrm{SiO}_{2}[1]$.

$\mathrm{SiO}_{2}$ forms a network solid crystal (tectosilicates) in which each silicon atom is bonded to four oxygen atoms. It would, therefore, seem that the formula should be $\mathrm{SiO}_{4}$, but each oxygen atom is bonded to another silicon atom as well [2].

Therefor every silicon atom has four half-oxygen which means that silicon atom is bonded to two oxygen atoms Fig. 1.

Sand is a product of weathering processes, which causes the disintegration or decomposition of rock near the surface of the earth.

\footnotetext{
*corresponding author; e-mail: sabiha.anas@gmail.com
}

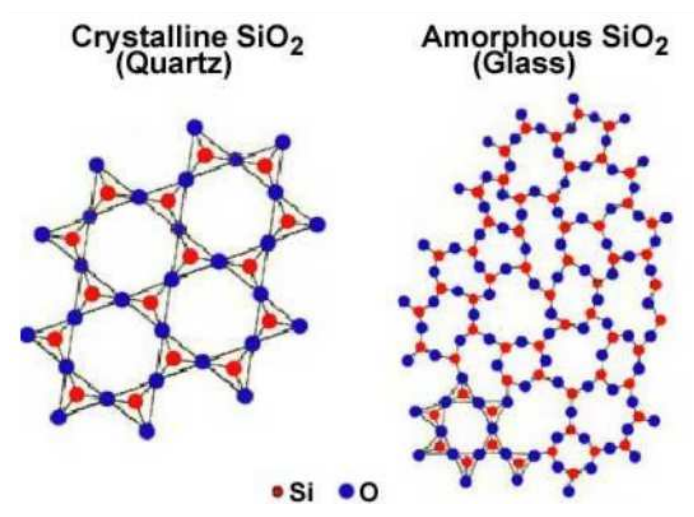

Fig. 1. Schematic of silica molecule.

Sand is considered as a clastic rock with a total absence of cement, whose size lies between 0.05 to $2 \mathrm{~mm}$.

Although these grains may be of any mineral composition, the dominant component of sand is the mineral quartz, which is composed of silica (silicon dioxide). Sand can include other components like aluminium, sodium, calcium and potassium (feldspar minerals). Ferromagnesian minerals are silicate minerals in which cations of iron and magnesium form essential chemical components. The term is used to cover such minerals as the olivines, pyroxenes, amphiboles, and the micas biotite and phlogopite.

For a particular source of sand to be suitable for industrial application, it must not only contain a very high proportion of silica but it also should not contain more than strictly limited amounts of certain metallic elements such as iron, aluminium, titanium, etc. 
Silica sand is also normally required to be well-sorted, i.e. to have grains of an approximately uniform size. Industrial uses of silica sand depend on its purity and physical characteristics. Some of the more important physical properties are: grain size and distribution, grain shape and sphericity. Silica sands have a large number of uses depending on their characteristics [3]:

- Production of silicon and silicon carbide, production of glass.

- Foundry sand, ceramics.

- Sandblasting and other abrasives

- Building products, filler and extender

- Pigments, hydraulic fracturing and propping in the oil industry

- Ultra high silica products in the electronic and fiber optic industries, fused silica, silicone products.

- Water filtration.

Algeria is a very large sunny country which makes it an important reservoir of solar energy. This solar radiation can be converted to electricity using photovoltaic solar panels. These are, mainly, manufactured of silicon cells, which are quite expensive. There are huge quantities of quartz $\left(\mathrm{SiO}_{2}\right)$, which is found in the sands although there are no producers of silicon in Algeria.

To our knowledge, the amount of quartz, that has a great economic importance, in the sand of Mostaganem has not been evaluated up to now. The main aim of this work is to evaluate several proprieties of the Mostaganem sand required for production of photovoltaic-grade silicon.

\section{Materials and methods}

\subsection{Geological setting}

Mostaganem is located in the in northwest Algeria. The area of the city is about $2.269 \mathrm{~km}^{2}$. Its geographical coordinates are: latitude of $35^{\circ} 55^{\prime} 57^{\prime \prime}$ North, longitude of $0^{\circ} 05^{\prime} 21^{\prime \prime}$ East, Fig. 2. The city of Mostaganem is lo-

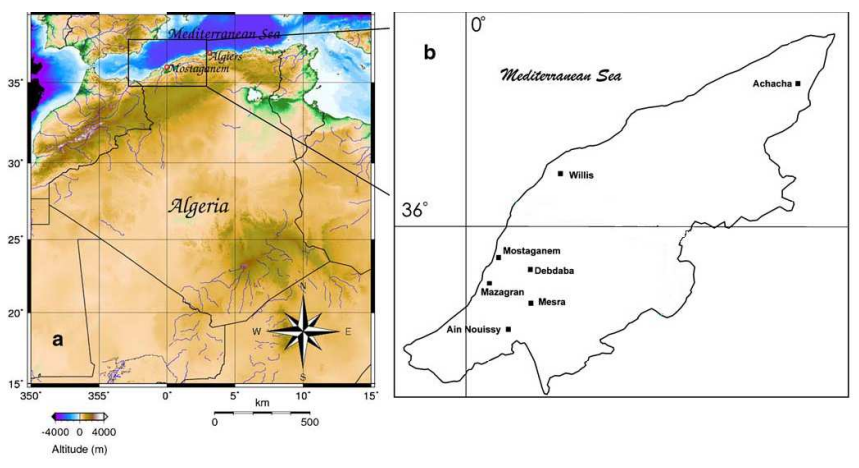

Fig. 2. Location of Mostaganem in Algeria [5, 6]. cated in the vicinity of Chlef in the east, of Relizane in the southeast, of Oran in the west, and of Mascara in the southwest. Mostaganem city is a littoral town. The climate is semi-arid, mild in winter and slightly humid at elevations greater than $500 \mathrm{~m}$ [4].

Our six sand (SM1, SM2, SM3, SM4, SM5 and SM6) samples were collected in this city.

The stratigraphy of the site is presented in Fig. 3.

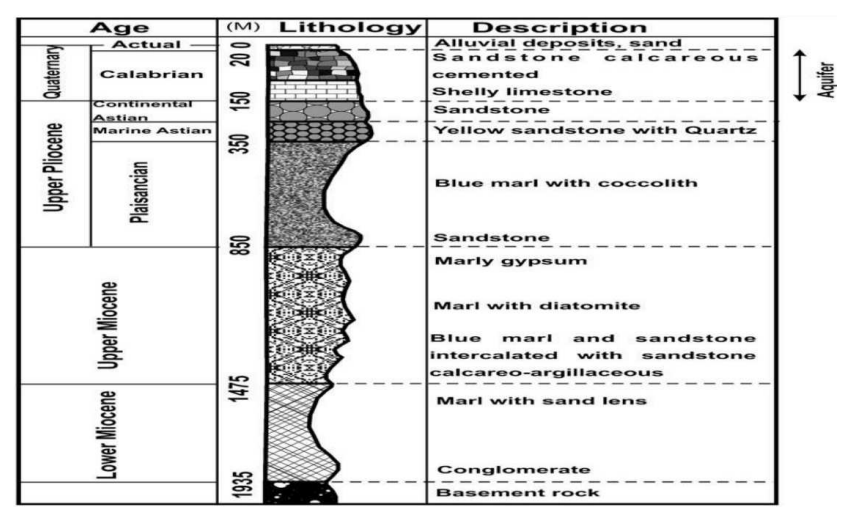

Fig. 3. Schematic stratigraphic section of the Mostaganem area [5].

\subsection{X-ray fluorescence analysis}

Chemical composition of the six samples, in their oxide form, was determined by employing an Axios Panalytical $\mathrm{X}$-ray fluorescence instrument in the department of geology of the National Office of Research in Geology and Mineralogy (ORGM, Boumerdes, Algeria)

Samples were first milled in a laboratory disc mill to approximately $40 \mu \mathrm{m}$ before pressing into pellets (approx. $5 \mathrm{~g}$ of sample material) and analyzed.

\subsection{X-ray diffraction analysis}

$\mathrm{X}$-ray powder diffraction (XRD) is a rapid analytical technique primarily used for phase identification of a crystalline material and can provide information on unit cell dimensions.

Knowledge about crystallinity is highly relevant, as a crystalline form is usually preferred in development. In contrast to amorphous material, the crystal has welldefined properties (melting point, solubility), parameters that should be known in order to control the final product. The result from an XRD analysis is a diffractogram showing the intensity as a function of the diffraction angles.

Our results of XRD analysis were obtained by means of Siemens D500 analyzer in the Department of Materials Science of the University of Biskra, Algeria.

After the XRF analysis, we conclude that our sand is very rich in silica so that the concentration of other minerals is almost the same. This is why the analysis was carried out only for sample SM1. For the analysis, sample SM1 was milled in a laboratory disc mill to approximately $63 \mu \mathrm{m}$. 


\subsection{Infrared absorption spectroscopy}

Infrared spectroscopy (FTIR) is one of the most interesting ways to study materials. It can be used to obtain the material structure without affecting its properties. Infrared spectroscopy exploits the fact that molecules absorb light with specific frequencies that are characteristic of their structure. It is often used to identify structures because functional groups give rise to characteristic bands both in terms of intensity and frequency. Infrared spectroscopy is a simple and reliable technique widely used in both organic and inorganic chemistry, in research and industry.

Sample SM1 was first milled in a laboratory disc mill to approximately $40 \mu \mathrm{m}$ and then formed into a $\mathrm{KBr}$-reach pellet for spectroscopic examination using a Brucker spectrometer in the laboratory of FTIR analysis of the Research Center of semiconductors for Energetic Application CRTSE, Algiers Algeria.

About $1.5 \mathrm{mg}$ of carefully ground sand was mixed with $100 \mathrm{mg}$ of dried $\mathrm{KBr}$ powder and then the mixture was further ground using a mortar and pestle. The mixture was then pressed in a hydraulic press to make a pellet, which was subsequently used for recording of the FTIR spectrum.

\subsection{Grain size analysis}

In this analysis we have used the sifting method, because it can separate sand from gravel and clay [7].

For this purpose we have used a mechanical sifter with ten sieves. We have used a dry-sieve analysis to determine the particle size distribution [8], or grading, of the sample. To obtain a grading, the aggregate is shaken through a series of sieves, nested one above the other in order of increasing opening size. The sieve with the largest openings is on top and the one with the smallest openings is on the bottom. A pan placed beneath the sieves catches material passing through the smallest sieve. Coarse and fine aggregate usually are sieved separately.

There are various indices which can be measured using this technique. In this work we have just measured the concentration in several sieves.

The grain size analysis was carried out at the metallurgy laboratory of the national company of the industrial vehicles (SNVI) in Rouiba (Algiers Algeria), using mechanical sifter RETSCH-AS 200.

\subsection{Microscopy observations}

In order to determinate the shape of the sand grain, scanning electron micrographs of the sand samples were obtained using JSM-5500LV/JSM-5500 in the Department of Materials Science of the University of Biskra, Algeria.

Optical micrographs of the sand samples were obtained using Nikon Eclipse E600 at the metallurgy laboratory of the national company of the industrial vehicles (SNVI) in Rouiba (Algiers Algeria).

\section{Results and discussion}

\subsection{X-ray fluorescence analysis}

According to Table I, we show that Mostaganem sand is very rich in silica $99.5 \%$. This sand has a small concentration of alumina and hematite and even smaller concentration of other oxides, such as the pyrite, the free rutile, the ilmenite, limonite and magnetite, which were also found in the raw material.

Chemical analysis of the content of Mostaganem sand [\%].

TABLE I

\begin{tabular}{c|c|c|c|c|c|c|c|c|c|c}
\hline \hline Oxides & $\mathrm{SiO}_{2}$ & $\mathrm{Al}_{2} \mathrm{O}_{3}$ & $\mathrm{Fe}_{2} \mathrm{O}_{3}$ & $\mathrm{CaO}$ & $\mathrm{MgO}$ & $\mathrm{Na}_{2} \mathrm{O}$ & $\mathrm{K}_{2} \mathrm{O}$ & $\mathrm{TiO}_{2}$ & $\mathrm{MnO}$ & $\mathrm{P}_{2} \mathrm{O}_{5}$ \\
\hline $\mathrm{SM} 1$ & 99.5 & 0.20 & 0.23 & 0.06 & 0.05 & $<0.05$ & $<0.05$ & $<0.05$ & $<0.05$ & $<0.05$ \\
$\mathrm{SM} 2$ & 99.4 & 0.20 & 0.28 & 0.011 & 0.05 & $<0.05$ & $<0.05$ & $<0.05$ & $<0.05$ & $<0.05$ \\
$\mathrm{SM} 3$ & 99.48 & 0.20 & 0.25 & 0.06 & 0.05 & $<0.05$ & $<0.05$ & $<0.05$ & $<0.05$ & $<0.05$ \\
$\mathrm{SM} 4$ & 99.52 & 0.20 & 0.23 & 0.08 & 0.05 & $<0.05$ & $<0.05$ & $<0.05$ & $<0.05$ & $<0.05$ \\
$\mathrm{SM} 5$ & 99.55 & 0.20 & 0.28 & 0.06 & 0.05 & $<0.05$ & $<0.05$ & $<0.05$ & $<0.05$ & $<0.05$ \\
$\mathrm{SM} 6$ & 99.45 & 0.25 & 0.23 & 0.06 & 0.05 & $<0.05$ & $<0.05$ & $<0.05$ & $<0.05$ & $<0.05$
\end{tabular}

\subsection{X-ray diffraction analysis}

In order to determine the parameters and the structure of the crystal lattice of our sand samples, we have used the X-ray diffraction which turns out to be the only technique for the determination of these parameters. The XRD spectrum of Mostaganem sand is shown in Fig. 4.

In Table II, we observe the appearance of all peaks related to the presence of alpha-quartz in our sand sample, confirming the high crystallinity.
According to these results, we attest the absence of other phases than quartz, which confirms the results found by XRF.

When we compare between the results found by the $\mathrm{XRD}$ and those presented in the jcpds 46-1045 card (ASTM card), also shown in Table II, we certify that there is a very good similarity between the measured parameters and those present in this card.

The software used for data analysis and for the $\mathrm{Ri}$ etveld refinement was HighScore Plus from PANalytical. 


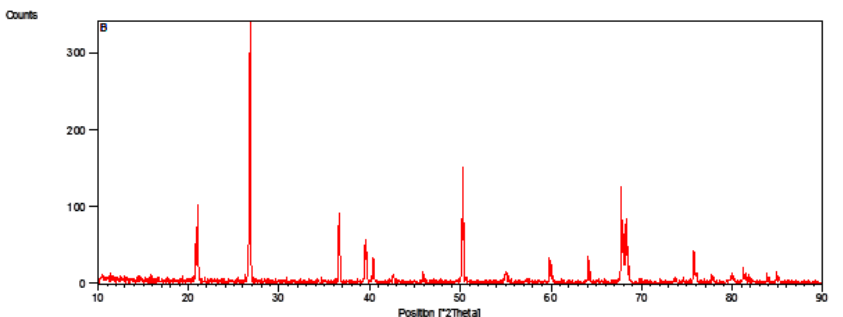

Fig. 4. XRD spectrum of Mostaganem sand.

TABLE II

Parameters of XRD peaks of Mostaganem sand and reference parameters.

\begin{tabular}{c|c|c|c|c|c|c|c}
\hline \hline \multicolumn{3}{|c|}{ Measured parameters } & \multicolumn{4}{|c}{ jcpds 46-1045 } \\
\hline Peak & $2 \theta$ & $D$ hkl & $\begin{array}{c}\text { Intensity } \\
{[\%]}\end{array}$ & $2 \theta$ & $D$ hkl & $\begin{array}{c}\text { Intensity } \\
{[\%]}\end{array}$ & HKL \\
\hline 1 & 21.0283 & 4.22482 & 6.34 & 20.859 & 4.2550 & 16.0 & $(100)$ \\
2 & 26.8635 & 3.31891 & 100.00 & 26.639 & 100.0 & 3.3435 & $(101)$ \\
3 & 36.6860 & 2.44971 & 11.28 & 36.543 & 2.4569 & 9.0 & $(110)$ \\
4 & 39.4900 & 2.28200 & 4.35 & 39.464 & 2.2815 & 8.0 & $(102)$ \\
5 & 40.3841 & 2.23351 & 2.55 & 40.299 & 2.2361 & 4.0 & $(111)$ \\
6 & 42.4300 & 2.13043 & 0.80 & 42.449 & 2.1277 & 6.0 & $(200)$ \\
7 & 46.1200 & 1.96821 & 0.08 & 45.792 & 1.9799 & 4.0 & $(201)$ \\
8 & 50.2382 & 1.81610 & $11 ., 45$ & 50.138 & 1.8180 & 13.0 & $(112)$ \\
9 & 50.6800 & 1.80130 & 0.21 & 50.621 & 1.8017 & $<1$ & $(003)$ \\
10 & 54.7600 & 1.67635 & 0.08 & 54.873 & 1.6717 & 4.0 & $(202)$ \\
11 & 55.2700 & 1.66209 & 0.16 & 55.323 & 1.6592 & 2.0 & $(103)$ \\
12 & 57.1900 & 1.61077 & 0.15 & 57.234 & 1.6083 & $<1$ & $(210)$ \\
13 & 59.8582 & 1.54519 & 3.46 & 59.958 & 1.5415 & 9.0 & $(211)$ \\
14 & 63.9100 & 1.45665 & 0.13 & 64.034 & 1.4529 & 2.0 & $(113)$ \\
15 & 65.8300 & 1.41874 & 0.08 & 65.784 & 1.4184 & $<1$ & $(300)$ \\
16 & 67.7892 & 1.38243 & 13.45 & 67.742 & 1.3821 & 6.0 & $(212)$ \\
17 & 68.2976 & 1.37338 & 6.08 & 68.142 & 1.3750 & 7.0 & $(203)$
\end{tabular}

The crystallographic parameters of Mostaganem sand have been determined through analysis of X-ray diffraction. These parameters were found to be as follows: hexagonal crystal system, space group $\mathrm{P}_{3} 221$, unit cell parameters: $a=b=4.9030 \AA, c=5.3999 \AA$.

\subsection{Infrared absorption spectroscopy}

The experimental FTIR absorption spectrum of studied sand is shown in Fig. 5.

\section{TABLE III}

The main bands of IR absorption and associated bond vibration of Mostaganem sand.

\begin{tabular}{c|c}
\hline \hline Frequency $\left[\mathrm{cm}^{-1}\right]$ & Vibration kind \\
\hline 459.75 & $\mathrm{Si}-\mathrm{O}-\mathrm{Si}$ \\
693.25 & $\mathrm{Si}-\mathrm{O}$ vibration \\
778.34 & $\mathrm{Si}-\mathrm{O}$ vibration \\
790.90 & $\mathrm{Si}-\mathrm{O}$ vibration \\
1080.72 & stretching vibrations $\mathrm{Si}-\mathrm{O}-\mathrm{Si}$ \\
1163.53 & stretching $\mathrm{Si}-\mathrm{O}-\mathrm{Si}$ bond \\
$1616.37-1876.23-3349.23$ & Stretching H-OH
\end{tabular}

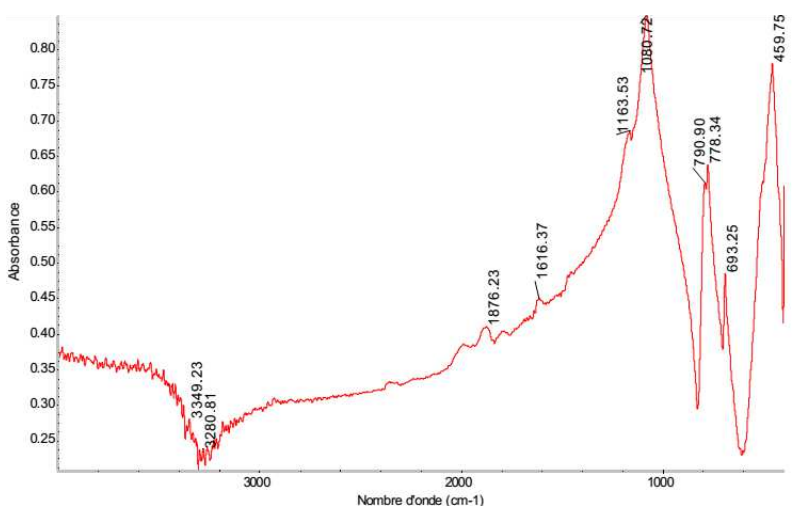

Fig. 5. FTIR absorption spectrum of Mostaganem sand.

The main bands of absorption obtained from Fig. 5, are shown in Table III [9-11].

\subsection{Granulometric analysis}

Sand samples were dried at $120^{\circ} \mathrm{C}$ for one hour and a half in an oven. After this the sieving operation was carried out. After studying the grain size distributions of the six samples, we have concluded that they are almost similar and for this reason here we present only the results of the grain size analysis of sample SM1. The results of granulometric analysis are shown as histogram in Fig. 6.

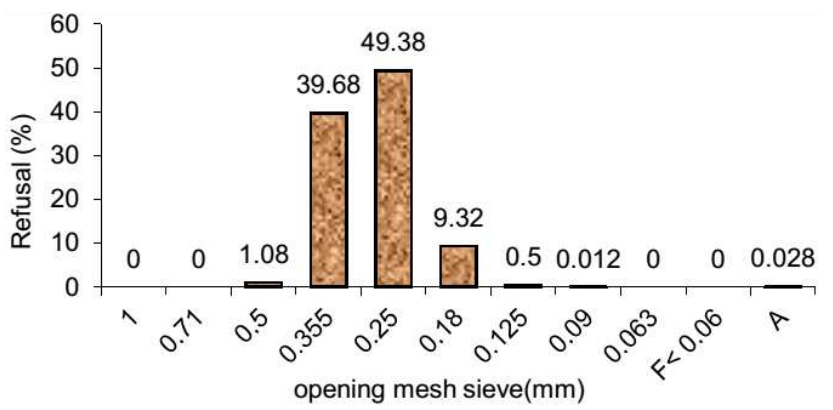

Fig. 6. Histogram representation of granulometric analysis of Mostaganem sand.

TABLE IV

Granulometric analysis.

\begin{tabular}{c|c}
\hline \hline Opening size of sieve $[\mathrm{mm}]$ & Refusal [\%] \\
\hline 1.4 & 0 \\
1 & 0 \\
0.71 & 0 \\
0.5 & 1.08 (corse sand) \\
0.355 & 39.68 (corse to medium) \\
0.25 & 49.38 (medium to fine) \\
0.18 & 9.32 (fine sand) \\
0.125 & 0.5 \\
0.09 & 0.012 \\
0.063 & 0 \\
F $<0.06$ & 0 \\
A & 0.028
\end{tabular}


After the analysis of the obtained results, we notice that in the size distribution of Mostaganem sand prevail grains in the class of $0.25 \mathrm{~mm}$ and $0.355 \mathrm{~mm}$. These classes represented almost 50 to $40 \%$ of the overall mass of the sand.

In the particle size class of $0.18 \mathrm{~mm}$ we find almost $9 \%$, while the concentration is insignificant in the remaining sieves.

\subsection{The microscopy observations}

\subsubsection{Optical microscopy observation}

The micrographs at lower magnifications in Fig. 7 reveal the presence of somewhat rounded, angular edged, elongated and irregular grains.

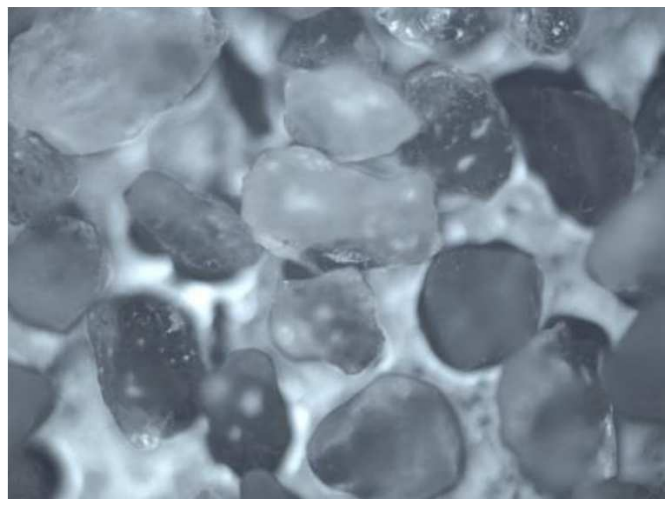

Fig. 7. Mostaganem sand micrograph.

\subsubsection{Scanning electron microscopy observations}

The observation under the scanning electron microscop confirms the irregular shape of sand. Figure 8a confirms the rounded shape of sand and that the grain dimensions are about $200 \mu \mathrm{m}$ in average.
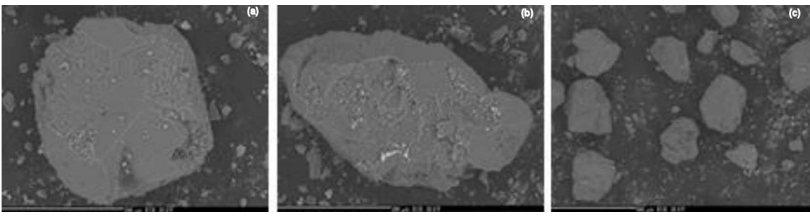

Fig. 8. Scanning electron micrographs of Mostaganem sand.

Figure $8 \mathrm{~b}$ confirms the elongated shape of sand grains and that their dimensions are about $400 \mu \mathrm{m}$ in average.

Figure $8 \mathrm{c}$ shows several shapes of sand, including somewhat elongated, rounded and angular shape with various dimensions.

\section{Conclusions}

The present work has been carried out using several characterization techniques in order to assess applicability of Mostaganem sand for photovoltaic applications.

According to X-ray fluorescence analysis, we certify that Mostaganem sand is very rich in silica $99.5 \%$. The X-ray diffraction reveals that Mostaganem sand has a high crystallinity. The crystallographic parameters were found to be as follows: hexagonal crystal system, space group $\mathrm{P}_{3} 221$, unit cell parameters: $a=b=$ $4.9030 \AA, c=5.3999 \AA$. The FTIR spectrum of this sand indicates that the majority of chemical bonds were $\mathrm{Si}-\mathrm{O}$ bonds, with different kinds of vibrations. Especially the double absorption at 790 and $7798 \mathrm{~cm}^{-1}$ indicates that the sand is in $\alpha$-quartz phase.

The granulometric analysis shows that in the size distribution of Mostaganem sand prevail grains with the size of $0.25 \mathrm{~mm}$ and $0.355 \mathrm{~mm}$.

Using the optical microscopy and the scanning electron microscopy, we observed that the sand grains are rounded, angular edged, elongated and irregular.

After the study of several proprieties of the Mostaganem sand, we conclude that this sand can be used in photovoltaic applications by the reduction of silica with carbon in an electric arc furnace [12] at temperatures higher than $2000{ }^{\circ} \mathrm{C}$ in the hottest parts, by a reaction that can be written ideally as:

$\mathrm{SiO}_{2}+2 \mathrm{C}=\mathrm{Si}+2 \mathrm{CO}[13]$.

We confirm that Mostaganem silica can be used as the raw material for production of silicon.

\section{Acknowledgments}

This work was completed thanks to the National Funds of Research, DGRSDT/MESRS (Algeria) and to the invaluable assistance of Miss Abellache Dahbia, member of the metallurgy laboratory of the national company of the industrial vehicles (SNVI Rouiba), whom we wish to thank.

\section{References}

[1] W. Trabelsia, M. Benzinab, S. Bouaziza, Phys. Procedia 2, 1461 (2008).

[2] S. Beddiaf, S. Chihi, Y. Leghrieb, J. Afr. Earth Sci. 106, 129 (2015).

[3] K. Shah Ariffin, What is Silica EBS 425 - Mineral Perindustrian, 2004.

[4] Z. Bendjoudi, F. Taleb, F. Abdelmalek, A. Addou, Waste Manage. 29, 1383 (2009).

[5] F. Bahri, H. Saibi, Arab. J. Geoscience (2010).

[6] F. Belhouari, K. Bendani, H. Missoum, M. Derkaoui, Arab. J. Sci. Eng. (2015).

[7] A. Tafraoui, S. Lebaili, A. Slimani, Res. J. Appl. Sci. 1, 1 (2006).

[8] M.I. El-Sayed, Sediment. Geol. 123, 219 (1999).

[9] M. Hatipoglu, J. Afr. Earth Sci. 54, 1 (2009).

[10] R.L.P. Carnina, M. Valadares Folguerasb, R.R. Luvizaob, S.L. Correiab, C.J. da Cunhac, R.S. Dungand, Thermochim. Acta 543, 150 (2012).

[11] I. Štyriaková, A. Mockovčiaková, I. Štyriak, I. Kraus, P. Uhlík, J. Madejová, Z. Orolínová, Appl. Clay Sci. 61, 1 (2012).

[12] E. Dal Martello, G. Tranell, S. Gaal, O.S. Raaness, K. Tang, Metall. Mater. Trans. B 42B, 939 (2011).

[13] K. Aasly, Ph.D. Thesis, Trondheim 2008. 